\title{
El sargento Canuto, un esbozo de la mujer moderna
}

\section{Gabriela Schiappacasse $^{1}$ \\ Universidad Científica del Sur \\ gabriela.schiappacasse@gmail.com}

\section{RESUMEN}

El presente artículo está basado en la obra El sargento Canuto, del dramaturgo peruano Manuel Ascencio Segura, que da una mirada adelantada al concepto de mujer de la época y lo representa en la figura de Jacoba, quien establece una relación de poder sobre las decisiones de su padre, representante de la dominación masculina.

\section{PALABRAS CLAVE}

Costumbrismo, goal, feminismo, patriarcado, pulsión.

\section{ABSTRACT}

This article is based on the play El Sargento Canuto, it belong's to the peruvian playwright Manuel Ascencio Segura, who writes about the concept of women of his time with another point of view wich is not the tradicional and it is represented in the figure of Jacoba, who establishes a relationship of power over decisions to his father who represents male dominance.

\section{KEY WORDS}

Costumbrismo, goal, feminism, patriarchy, impulse. 
El sargento Canuto (1839) es una obra del dramaturgo Manuel Ascencio Segura (Lima, 23 de junio de 1805-Lima, 18 de octubre de 1871) perteneciente al costumbrismo peruano, movimiento artístico que busca satirizar el comportamiento y resaltar los defectos de las personas para intentar corregirlos. El costumbrismo está influenciado por el neoclasicismo y el romanticismo, periodos previos que dan origen a este movimiento. Se inició en España en 1820 y llegó a América Latina a través de los cuadros de costumbres. No solo se reflejó en la literatura: también aparecieron las pinturas costumbristas y los cuadros de costumbres. Eva Valero (2005: 353) afirma:

En este contexto, la literatura que emergió tras la independencia encontró en el modelo del costumbrismo español el género más amable para la construcción literaria de la nueva Lima criolla. Esta continuaba siendo el centro del poder en un extenso país, el Perú, en el que el secular divorcio entre la costa y la sierra -entre los criollos y los indígenas - y la consecuente problemática social no se resolvió, como era de esperar, tras la separación de la metrópoli. El cuadro de costumbres de la clase media limeña fue el reflejo de esta realidad decimonónica en la que la Lima del presente se convirtió en protagonista indiscutible. Deliberadamente se borró el pasado de los espacios de la escritura, reservados para la representación de la actualidad en un discurso moralizante que garantizara la prosperidad del mañana, como los cuadros de Felipe Pardo y Aliaga, o a través de la punzante ironía del mejor retratista de aquella realidad, Manuel Asencio Segura. Las características del cuadro de costumbres hispánico, con Larra y Mesonero Romanos como máximos representantes, eran ideales para plasmar la nueva sociedad hispanoamericana nacida de la Independencia, de manera que el género se aclimató rápidamente a la realidad americana.

El costumbrismo se inicia en 1829 con el estreno de Felipe Pardo y Aliaga Frutos de la educación, alcanza su máximo esplendor con la fundación del periódico El Espejo de mi Tierra (1840), de Pardo, y culmina con la comedia Las tres viudas (1862), de Manuel Ascencio Segura. En este movimiento la clase elitista, representada en la figura de Pardo y Aliaga, se confronta con la clase media y popular a través de Segura. Ambos tratan de reflejar aquello que asumen como ridículo y banal, lo cual se ve respaldado con los artículos de costumbres, que cuentan con mayor repercusión. Jannet Torres (2009: 315) afirma lo siguiente:

Los artículos de costumbres, a pesar del tiempo transcurrido desde las primeras décadas del siglo XIX en que alcanzaron su mayor apogeo, aún poseían un estatus por el que eran reconocidos y aceptados, ya que sintetizaban dos preceptos que se demandaban en la 
literatura de la época: eran útiles y agradables. Eran útiles dado que la crítica que explícita o implícitamente contenían buscaba normativizar la vida, la cultura e instituir el orden. Eran agradables por el simple hecho de que optaban por el tono humorístico antes que adusto para socavar las malas costumbres: evitan el shock del ataque frontal $y$, mediante el juego de ingenio, subvierten «la normalidad» de los vicios desnudándolos en su dimensión risible y deleznable. Probablemente, es por las cualidades señaladas que en la Lima de fines del siglo XIX, en medio del desgobierno y el caos, el artículo costumbrista encuentra nuevamente acogida.

La obra relata los intentos fallidos de un militar (Canuto) que intenta casarse con una muchacha de clase media (Jacoba) y busca convencer al padre de ella; obtendrá un ascenso social para toda su familia si el padre aprueba el matrimonio y se valdrá de falsas hazañas para engrandecerse.

\section{La mujer del XIX y la «mujer» dentro de la obra}

El prototipo de la mujer costumbrista viene ligado a la concepción de mujer que se estableció desde la época del humanismo: una mujer que debía permanecer en silencio y obedecer las órdenes del género masculino (padre, hermano, marido). Segura intentó resquebrajar esta idea en El sargento Canuto.

En despectiva actitud, casi todos los pensadores españoles de la época del humanismo opinaban que la mujer debía hablar poco o, mejor aún, callar. En este sentir coincidían fray Luis de León, Juan Luis Vives, Juan de la Cerda, el doctor Huarte de San Juan, Bartolomé de Medina, Cristóbal de Medina, entre otros. Sus conceptos misóginos reposaban en la autoridad de Aristóteles, la Biblia y los padres de la Iglesia. De manera concreta, Juan de la Cerda (Vida política de todos los estados de las mujeres, 1599, citado en Guardia 2013: 109) apuntaba:

Muy sano consejo es para las mujeres rogarles que sean calladas, pues son poco sabias. [...] es justo que se precien de callar todas, así aquellas a quienes les conviene encubrir su poco saber como las que pueden sin vergüenza descubrir lo que saben, porque en todas no es solo condición agradable, sino virtud debida en silencio el hablar.

Las mujeres han sido tomadas desde tiempos remotos bajo el rol de esposa y madre, lo cual lo comentará y sentenciará años después Clorinda Matto de Turner (Cusco, 11 de septiembre de 1852-Buenos Aires, 25 de octubre de 1909) en su libro Herencia (1893), al referirse al rol de las madres que deben educar a sus hijos sin haber ellas recibido educación alguna.

Una de las restricciones del rol femenino, es decir, el papel que cumplían las mujeres del siglo XIX, las excluía de escribir o participar de 
reuniones literarias, movimientos políticos, y demás actividades que implicaran movimiento de masas e ideología. Rocío Ferreira (2009: 1) sostiene:

En el primer número de su revista literaria argentina, Búcaro Americano. Periódico de las Familias, Clorinda Matto de Turner publicó su ensayo «Las obreras del pensamiento en la América Latina», que presentó en el prestigioso Ateneo de Buenos Aires el 14 de diciembre de 1895. En la primera parte de su ensayo - cita que hemos usado como epígrafe del presente estudio-Matto de Turner consolida su posición como mujer en el campo intelectual decimonónico panamericano, y recordando su experiencia personal, y tal vez la de su compatriota Mercedes Cabello de Carbonera, establece las grandes dificultades por las que tiene que atravesar la escritora para cumplir con su misión civilizadora y lograr un espacio en la ciudad letrada.

La figura de las mujeres del costumbrismo es la figura de aquellas que se mantuvieron dentro de un estereotipo que se rompe dentro de la representación de Jacoba y Nicolasa en la obra de Segura.

Judith Butler, en su libro El género en disputa, plantea la idea de una identidad femenina de identificación colectiva que parte desde el nombre (el cual puede ser considerado como un aspecto básico) hasta la imposición de la moda, los colores, el comportamiento, el peinado, entre otros rasgos que marcan la definición de mujer en diferentes periodos. Esta idea nos brinda una delimitación inicial para poder esbozar la idea de las mujeres en el siglo XIX respecto a su rol social y una estricta política de representación.

La primera imagen que se trae a la mente es la de la vestimenta, la cual sirve para una identificación masiva que ayuda a delimitar la época. Las mujeres tenían que usar la ropa de acuerdo con su clase social: los vestidos de arpón eran para aquellas que pertenecían a la clase burguesa, las tapadas tenían trajes mucho más sencillos y un manto que les cubría la mitad de la cara, las mujeres de clase media no llevaban vestidos con excesivo recargo y las esclavas tenían vestidos extremadamente sencillos. Cabe resaltar que este aspecto no pertenece solo al siglo XIX, ni tampoco es exclusivo del periodo costumbrista. En diferentes épocas y culturas la ropa ha marcado la clase social.

A causa de esta figura de mujer establecida, la representada en la obra de Segura bajo el personaje de Jacoba descuadra a quien se acerca con una idea convencional. Ella no tenía poder para discutirle a su padre con quién deseaba casarse, ni podía decidir de quién enamorarse; el matrimonio era una mera convención, por lo cual el desposarla con Canuto significaba un notorio ascenso social, a pesar de que la imagen que tenía el 
padre de su futuro yerno estaba completamente distorsionada debido a la falsa grandeza formada por el deseo de Canuto de conseguir su objetivo.

Dentro de la obra, los personajes femeninos presentan una ligera discordancia, ya que Jacoba, a diferencia de su hermana Nicolasa, presenta un carácter decisivo frente a lo destinado por su padre y siempre levanta la voz para dar a conocer su opinión y aquello que cree es correcto para ella. Nicolasa, en cambio, escucha a su padre y no le objeta, pero tampoco cumple con lo ordenado.

JACOBA. Ya no se puede aguantar

tal desvergüenza. ¿Qué es esto?

Es usted, el que muy presto

se debe mandar mudar

de aquí... igua!, igua!, pues no es buena

que, porque usa usted casaca,

quiera con tanta alharaca

disponer de casa ajena

como si...

Para explicar el carácter de nuestra figura femenina principal dentro de la obra, tomamos en cuenta lo establecido por Slavoj Žižek en su libro Mirando al sesgo. Žižek reformula los conceptos de psicoanálisis lacaniano para explicar la idea de pulsión y objeto de deseo, y plantea que la mirada distorsionada de aquello que se anhela es lo que lleva al individuo a obtener aquello que siente es necesario para su bienestar.

En este caso, Jacoba, al igual que Canuto, es un personaje que busca concretar su idea de realización al contraer matrimonio con Pulido. Sin embargo, es a causa de esta meta que ella desobedece a su rol como hija, coloca antes que la obediencia a su padre su decisión para escoger con quién desposarse y busca la manera de desenmascarar a Canuto para demostrar que él no es lo que verdaderamente se piensa.

Es así como entendemos que Segura presenta una mujer que está dispuesta a materializar sus decisiones por medio de acciones que le permitan demostrar que está actuando bajo los criterios de verdad que se esconden en el discurso construido por Canuto para convencer a su padre.

El carácter de Jacoba se respalda en su hermana, quien la ayuda a armar la emboscada para poder derrotar el plan de Canuto. La identificación de ambas es lo que construye una identidad de mujeres diferentes en la obra, identidad que no se iguala al colectivo de la sociedad en la que vivían y que rompe con la política cultural que establece el patrón de una mujer de figura tradicional anteriormente descrita. Este rasgo se asemeja 
a Paquita de Frutos de la educación, de Felipe Pardo y Aliaga, quien también desobedece a su madre y continúa bailando la zamacueca y buscando el pretexto para no casarse con quien le habían destinado.

Un rasgo que es importante resaltar es que a ninguna de las dos se les presenta en la cocina en ninguna de las escenas. Los únicos espacios que comparten son la habitación, lugar donde confabulan y conversan en privado, y la sala, donde Jacoba se enfrenta a las decisiones de su padre.

El autor no solo está relegando a una mujer que cumple con labores domésticas, sino que las está colocando en espacios que no eran convencionales, es decir, con labores domésticas del diario vivir.

Jacoba es una mujer que piensa en ella misma, que crea estrategias para zafarse de la responsabilidad que le impone su padre. Siguiendo esta idea, Judith Butler (1992: 49) nos dice lo siguiente:

Sin embargo, aparte de las ficciones fundacionistas que respaldan la noción del sujeto, está el problema político con el que se enfrenta el feminismo en la presunción de que el término mujeres indica una identidad común.

De esta manera, Jacoba no es una mujer que encaje dentro del término mujer de la época, sino que empieza a resquebrajar el molde del estereotipo establecido en ese entonces.

El lenguaje también es un medio que emplea para complementar la brusquedad del personaje, lo cual ayuda a configurar esa figura de mujer transgresora y aguerrida que busca colocar en escena el dramaturgo. Ello lo vemos en el siguiente diálogo, en el que enfrenta a su padre.

JACOBA. Si yo me caso, señor, será con quien me acomode, que me tenga mucho amor, y que en nada me incomode.

DON SEMPRONIO. (Fuerte). Con quien yo quiera, al rigor.

JACOBA. ¡De otro modo, aunque me maten!

DON SEMPRONIO. Tú de Canuto serás;

si no mandaré que te aten

como a loca, y no querrás...

La figura del padre de Jacoba es retratada como autoritaria en el fragmento anteriormente citado, el cual no rompe con el estereotipo del padre de la época, sino que lo mantiene.

CANUTO. Don Sempronio...

DON SEMPRONIO. ¿Qué sucede? 
CANUTO. Pero, hombre, ¿no lo ve usted?

Después que le he hecho merced

de la vida, aún no me cede

el puesto este mo...

DON SEMPRONIO. ¿Qué cosa?

NICOLASA. ¡Habrase visto muñeco

más orgulloso y más hueco!

DON SEMPRONIO. La porfiada, jeh!, ¡í́, graciosa!

Sempronio es un padre que trata de imponer sus decisiones sobre la voluntad de su hija. Sin embargo, posteriormente reconocerá que fue víctima de una treta creada por Canuto y se verá dispuesto a conceder el pedido de Jacoba. De acuerdo con lo planteado por Yolanda Carballeira (2009: 2), la figura del padre de Jacoba se encuentra sujeta de cierto modo a la reivindicación mostrada por su hija a través de la rebeldía, rasgo que ella atribuye al siglo XIX:

Desde el Renacimiento a la edad moderna, el padre siguió teniendo autoridad total sobre la mujer y los hijos, y es a partir del siglo XIX que empieza a tener ciertas limitaciones. Por un lado, se encuentra bajo presión de las reivindicaciones de las mujeres y los hijos, y, por otro, el Estado va a ejercer una mayor tutela, sobre todo en las familias más carenciadas, como forma de proteger a los hijos de la negligencia paterna. El hijo empieza a tener derecho y el padre, obligaciones hacia él.

Esto supone un debilitamiento del estatus de padre, pero es de destacar, que aunque el Estado empiece a limitar los poderes del padre, su figura en el imaginario social seguía permaneciendo como el «padre terrible», el padre burgués.

Además, debemos resaltar que la figura materna está ausente en la obra. La casa está regida por el patriarcado de Sempronio y el único modelo femenino son las hijas. Ese vacío demuestra la autoridad del padre sobre la voluntad de las hijas. La madre, siendo mujer, no hubiera tenido otro rol aparte de apoyar las decisiones de su marido, cumpliendo con el rol de madre tradicional.

Esto no es impedimento para mostrar la conducta transgresora de las hijas, ya que la ausencia de la madre refuerza esta actitud. De esta manera, vemos cómo Jacoba completa su personaje aguerrido en los breves enfrentamientos que tiene con Canuto, su supuesto prometido, al cual siempre le afirma que el matrimonio que él tiene pensado no se realizará. Si fuera presentada como una mujer que sigue las normas del colectivo, ella no podría negarse ni discutir nada. 
JACOBA. ¡Vaya, que usted sueña!

Para mi marido,

es usted, querido,

muy muñeco, igua!;

un daca la seña;

un simple, un mangajo,

un sucio estropajo

que hasta asco me da.

La obra presenta una división de género en la que predomina el masculino. El género femenino está representado por dos personajes (Jacoba y Nicolasa), mientras que el masculino se ve respaldado por cuatro ( $\mathrm{Pu}$ lido, Sempronio, Canuto y Cazoleta). En estos últimos recae la fuerza de las decisiones y son quienes presentan el principal conflicto. No obstante, la mayor fuerza la tiene el género femenino, pues la decisión final viene ligada al esfuerzo de Jacoba y Nicolasa al desenmascarar a Canuto. Son figuras femeninas que comparten las decisiones tiranas del padre y que levantan la voz al momento de decidir sobre su futuro. Esta división corresponde al esbozo de la división social y de género de la época, como lo plantea Butler en la siguiente cita (1993: 49):

La creencia política de que debe haber una base universal para el feminismo, y de que puede fundarse en una identidad que aparentemente existe en todas las culturas, a menudo va unida a la idea de que la opresión de las mujeres posee alguna forma específica reconocible dentro de la estructura universal o hegemónica del patriarcado o de la dominación masculina.

Las acciones realizadas por Jacoba están movidas por el deseo de liberación del yugo patriarcal y por el deseo de realizarse junto al hombre que ama (Pulido), lo que la representa bajo los términos lacanianos como un personaje movido por la pulsión. Ella no lucha sola: se ve respaldada por dos aliados, Nicolasa y Pulido, pero solo con uno es con quien comparte el deseo de matrimonio; a ello Žižek (2010: 21) calificaría como el goal o la meta compartida, que se logra en compañía de los aliados:

Goal es el destino final, mientras que aim es lo que intentamos hacer, es decir, el camino en sí. Lo que trata de decir Lacan es que el propósito real de la pulsión no es su meta, sino su propósito. El propósito final de la pulsión consiste simplemente en reproducirse como pulsión, volver a su senda circular, continuar hasta y desde la meta. La fuente real del goce es el movimiento repetitivo en este circuito cerrado. 
Se puede apreciar en el siguiente extracto de la obra como es que con la ayuda de sus dos cómplices, Jacoba termina cumpliendo su cometido. Es respaldada por su hermana para poder resistirse a obedecer a Canuto y este es retado por Pulido para un duelo de pistolas, en el cual Canuto demuestra su cobardía.

CANUTO. Venga.

JACOBA. No quiero... ¡Ay, Colasa!

NICOLASA. (A Canuto). Déjela usted.

PULISO. (Descubriéndose). ¡Fuera embozo!

Al que chiste lo destrozo.

DON SEMPRONIO. ¡Silencio! ¡Quién en mi casa...

CAZOLETA. (Pulido le quita el fusil).

Al final de la obra, Jacoba logra su meta. Su padre acepta que se case con Pulido y es consciente de que fue engañado por las artimañas de falsa grandeza de Canuto. Ello refleja el triunfo de la decisión de su hija y la predominancia del poder que ha establecido la figura femenina sobre el patriarcado que estaba establecido.

Pero ¿hasta qué punto está estableciendo una idea de mujer moderna? El presentar a un personaje que levante la voz y se defina como una hija rebelde es esbozar a una mujer que con el tiempo va a aprender a decir no y hacer valer su palabra, una mujer que no solo se va a quedar a cumplir su rol en la cocina — como en un inicio la habían formado—, una mujer que buscará ser educada posteriormente para poder participar en decisiones importantes y tomar un lugar en la sociedad, en donde sea reconocida.

En condiciones generales, la mujer es hoy en día una figura que ha ganado diferentes espacios en los cuales se desenvuelve. Estamos enfrentándonos como individuos a una sociedad que busca dejar de regirse por el concepto de predominancia masculina y que trata de abrirle sus puertas a la igualdad del género femenino, lo cual esta abriendo un campo de mayor aceptación en los diferentes espacios sociales para la participación femenina.

Segura delimita un esbozo de mujer que se mantiene presente a través del carácter de Jacoba, no solo habiendo relegado sus labores domésticas sino al enfrentarse a espacios ya conquistados por el género femenino. Así logra una equidad social que le permite formar parte del desarrollo cultural. 


\section{REFERENCIAS BIBLIOGRÁFICAS}

BUTLER, Judith (1990). El género en disputa. Barcelona: Ediciones Paidós.

CARBALLEIRA, Yolanda (2009). «La evolución del lugar del padre a través de la historia y en la consulta terapéutica. Cambios en la estructura psíquica del niño actual». Consultado el 21 de abril de 2012 de http://www. sepypna.com/articulos/evolucion-lugar-padre-historia

FERREIRA, Rocío (2009). «Clorinda Matto de Turner, infatigable obrera del pensamiento». Consultado el 21 de abril de 2012 de http://www.guamanpoma.org/cronicas/11/Rocio_Ferreira.pdf

GUARDIA, Sara Beatriz (2013). Historia de las mujeres en América Latina. Murcia: Centro de Estudios La Mujer en la Historia de América Latina.

SEGURA, Manuel Ascencio (1839). El sargento Canuto. Lima: Editorial del Cardo.

TORRES, Jannet (2009). «Manuel Moncloa y Covarrubias y el artículo costumbrista en la prensa peruana de fines del siglo XIX». Consultado el 21 de abril de 2012 de http://revistas.pucp.edu.pe/index.php/boletinira/article/ view/4238/4210

VALERO, Eva (2005). «El costumbrismo y la bohemia romántica en el Perú: un tránsito hacia la "tradición"». Consultado el 21 de abril de 2012 de http://rua.ua.es/dspace/bitstream/10045/7251/1/ALE_18_26.pdf

ŽIŽEK, Slavoj (2000). Mirando al sesgo. Buenos Aires: Ediciones Paidós. 